\title{
Música para idosos institucionalizados: percepção dos músicos atuantes*
}

\author{
MUSIC FOR INSTITUTIONALIZED ELDERLY: PERCEPTIONS OF THE INTERVENING MUSICIANS \\ MÚSICA PARAANCIANOS INSTITUCIONALIZADOS: PERCEPCIÓN DE LOS MÚSICOS
}

\author{
Eliseth Ribeiro Leão', Victor Flusser ${ }^{2}$
}

\section{RESUMO}

Estudo qualitativo que analisou a percepção dos músicos sobre a atividade musical junto a idosos institucionalizados (Portugal e França). Empregaram-se um questionário e o Discurso do Sujeito Coletivo para organização dos dados. Os músicos percebem sua atuação como uma experiência relacional; buscam intencionalmente a proximidade e a comunicação; reconhecem a realidade dos idosos institucionalizados e desejam transformá-la; apresentam algumas dificuldades de comunicação interpessoal, de aprimoramento profissional e adotam critérios musicais, pessoais e intuitivos na escolha do repertório. Os resultados indicam o comprometimento social, humano e profissional dos músicos analisados e podem ser utilizados como fonte de reflexão aos profissionais de saúde.

\section{DESCRITORES}

Música.

Saúde do idoso institucionalizado.

Geriatria.

Comunicação não verbal.

\begin{abstract}
This qualitative study analyzed musicians' perception of their musical activities with institutionalized elderly in Portugal and France using a questionnaire and the Collective Subject Discourse to organize the data. The musicians see their performance as a human experience; they intentionally look for proximity and communication; they recognize the old persons' reality and wish to transform it; they present difficulties in interpersonal communication and in professional development, and adopt musical, personal and intuitive criteria when choosing their repertoire. The results indicate social, human and professional commitment from the musicians analyzed, and may be used as a source for reflection for the health team.
\end{abstract}

\section{KEY WORDS}

Music.

Health of institutionalized elderly.

Geriatrics.

Nonverbal communication.

\section{RESUMEN}

En este estudio cualitativo se tuvo como objetivo analizar la percepción de los músicos sobre la actividad musical con ancianos institucionalizados (Portugal y Francia). Se empleó un cuestionario y el Discurso del Sujeto Colectivo para la organización de los datos. Los músicos perciben su actuación como una experiencia de relación; buscan intencionalmente la proximidad y la comunicación; reconocen la realidad de los ancianos institucionalizados y desean transformarla; presentan algunas dificultades de comunicación interpersonal, de perfeccionamiento profesional y adoptan criterios musicales, personales e intuitivos en la elección del repertorio. Los resultados indican el compromiso social, humano y profesional de los músicos analizados y pueden ser utilizados como fuente de reflexión para los profesionales de salud.

\section{DESCRIPTORES}

Música.

Salud del anciano institucionalizado. Geriatría.

Comunicación no verbal.

\footnotetext{
* Extraído do trabalho de pós-doutorado "Musique et communication non-verbale dans des institutions de la santé: nouveaux matériaux pour la formation de musiciens intervenants em milieu de la santé", Université Marc Bloch, 2005-2006. ${ }^{1}$ Enfermeira. Doutora em Enfermagem pela Escola de Enfermagem, Universidade de São Paulo, Pós-Doutoranda pela Université Marc Bloch, França. Assessora de Pesquisa Científica do Hospital Samaritano, São Paulo, SP, Brasil. eliseth.leao@samaritano.com.br ${ }^{2}$ Docteur par L'Université D'Aix Marseille. Habilitation à Dirigeur des Recherches (HDR) par Université et Pays D’Ardour. Directeur du Centre de Formation de Musiciens Intervenants, Université Marc Bloch, Bischoffsheim, France. vflusser@yahoo.fr
} 


\section{INTRODUCÃ̃}

A população mundial está envelhecendo e a brasileira também. Segundo as estatísticas da Organização das Nações Unidas (ONU), em 1998 havia 66 milhões de pessoas com 80 anos ou mais no planeta. A estimativa da Organização Mundial da Saúde é de que até 2025, teremos 840 milhões de pessoas idosas, o que representa $70 \%$ de pessoas na $3^{a}$ idade em todo o mundo e o Brasil será o 60 país em número de idosos ${ }^{(1)}$.

A humanidade atravessa um ciclo de transição demográfica caracterizado pela queda acentuada das taxas de mortalidade e de fertilidade. A velocidade com que se processam as mudanças demográficas tem sido muito diferente entre o Brasil e os países desenvolvidos. Enquanto na França 115 anos deverão transcorrer antes que a proporção de idosos duplique, passando de $7 \%$ para $14 \%$, aqui o mesmo fenômeno deverá ocorrer em apenas 30 anos (de 7,7\% em 2020 para 14,2\% em 2050) ) $^{(2)}$. Por outro lado, os avanços tecnológicos e da medicina têm contribuído para um aumento da longevidade. Tais mudanças podem trazer sérias conseqüências à vida de muitas pessoas, uma vez que viver mais tempo não representa necessa-riamente viver bem.

Falar em envelhecimento implica entrar em um mundo de contradições, paradoxos e ambigüidades. Um dos aspectos que compõem a compreensão do envelhecimento e das formas de atuação efetiva, para que as condições preocupantes em que viviam os idosos nos séculos XIX e XX, na sociedade francesa, denunciadas por Simone de Beauvoir $^{(3)}$, tenham possibilidade cada vez menor de se repetir, diz respeito ao relacionamento interpessoal com os idosos no seu contexto de convivência e suas implicações para a qualidade de vida.

O relacionamento interpessoal está intimamente ligado aos processos de comunicação. No âmbito da comunicação verbal, a linguagem se destaca principalmente pela relação que guarda com os aspectos biológicos da consciência e o desenvolvimento do idoso. Podemos nos questionar se os profissionais da saúde estabelecem uma comunicação efetiva com os idosos, ou indo mais além, podemos questionar se existe uma comunicação efetiva entre os idosos e o seu meio social. Para um grande número de casos, acreditamos que não, pois, sabemos que em muitas situações de isolamento social, decorrentes da aposentadoria, da institucionalização do idoso, entre outras, a tão necessária demonstração de sensibilidade e da escuta atenta e interessada para que o relacionamento interpessoal ocorra, praticamente inexiste. A questão do asilamento, que configura a internação dos idosos em instituições de longa permanência, tem comprovado, ao longo do tempo, a ação da sociedade que descarta os indivíduos no momento em que deixam de ser saudáveis e produtivos ${ }^{(4)}$. Pensadas como cenários de cuidados, as Instituições de Longa Permanência (ILP), cuja demanda aumenta à medida que a população envelhece, ainda constituem um desafio, principalmente, se contrastadas com a proposta da promoção da saúde, que se funda no empoderamento, expresso, entre outros aspectos, pelo direito à individualidade, muitas vezes interditado neste contexto ${ }^{(5)}$.

Fato é, que o isolamento social retira os idosos dos círculos de linguagem significativa, o que pode levar o sistema de consciência a danos significativos, pois os processos de comunicação conferem o tônus afetivo e a qualidade da atividade simpática e parassimpática e por conseqüência, repercutem inclusive, na vitalidade das vísceras $^{(6)}$. A relação interpessoal, por vezes negligenciada, tem implicações diretas para com a saúde e a prevenção ou agravamento de doenças.

Vista assim, a consciência relaciona-se com a orientação do ser humano em seu ambiente social e cultural, regulando seu comportamento de acordo com a qualidade do seu sistema nervoso e a interação dada pela linguagem, que se torna significativa mediante os objetivos que orientam os idosos em seu grupo.

A retirada dos mais velhos do meio social inibe ou limita as estruturas da consciência, dos estados afetivos e da atuação das vias nervosas conscientes e inconscientes. A inserção do idoso em contextos sociais carregados de atividades significativas move-o a pensar e a querer, o que intensifica a atividade diencefálica ${ }^{(6)}$. Por outro lado, a diminuição de atividades significativas, com as respectivas interações verbais, conduz a que o idoso diminua tanto a perfusão cerebral como a interação entre as estruturas nervosas. Nesse contexto é de fácil compreensão a realidade patológica de idosos que perdem seus contatos íntimos por óbito, mudança de familiares, amigos ou outras formas de rompimento na comunicação, como também possibilita vislumbrar o que intervenções voltadas às interações humanas, nos mais diversos níveis, podem proporcionar, quando o asilamento é inevitável.

É nesse contexto que emerge o trabalho dos Músicos Atuantes no Âmbito da Saúde na Europa (ainda não desenvolvido no Brasil), denominado Música nos Hospitais, que propõe a cultura como um espaço para que a intersubjetividade dos processos comunicativos se expresse nas instituições de longa permanência, de que trata este trabalho e que pode nos remeter a importantes reflexões. O projeto Música nos Hospitais busca humanizar as instituições de saúde em diversos níveis, pois tem a premissa de favorecer a interação entre os músicos e os idosos (a que este estudo se restringe), entre 
os próprios idosos, entre os idosos e seus familiares/ acompanhantes, entre os profissionais da saúde e os idosos ou ainda, entre os próprios profissionais da equipe. Os músicos que atuam nesse projeto recebem a formação específica de um ano oferecida pelo Centro de Formação de Músicos Atuantes da Universidade Marc Bloch (França). Essa formação proporciona ao músico a aquisição de competências relacionais, organizacionais, aquisição de conhecimentos relacionados às regras e ao funcionamento das instituições de saúde, as especificidades das pessoas hospitalizadas ou em instituição e as formas e modalidades de intervenções musicais (o trabalho musical propriamente dito). Prevê um desenvolvimento crítico-reflexivo pessoal e os músicos recebem ainda, suporte psicológico durante o curso e seus estágios para lidarem com a dor, estresse, solidão, angústia e morte visando a reforçar os recursos internos para compartilhar desses aspectos com diferentes indivíduos nos hospitais.

Considerando fundamentos existencialistas, as relações humanas acontecem baseadas em princípios que originam dois tipos básicos de relacionamento, que podem ser chamados de relações do tipo Eu-Tu ou do tipo EuIsso. No primeiro caso, há verdadeiro comprometimento entre as pessoas envolvidas. No segundo, do tipo Eu-Isso, a relação é impessoal e não gera comprometimento verdadeiro. A vida do ser humano pode ser encarada como uma vida de comunicação com o outro, comunicação esta que estabelece a relação intersubjetiva. Quando encontramos o outro na relação que estabelecemos, no tipo de relação Eu-Tu, há uma mutualidade fundamentada na relação intersubjetiva plena do homem que é a liberdade como vivência. A consciência do homem de ser-com-o-outro-no-mundo, envolve, portanto, uma filosofia existencial $^{(7)}$. Nessa perspectiva, o referido projeto tem sido viabilizado pela formação específica de músicos naquela universidade (com curso satélite ministrado também em Portugal), para atuarem em instituições de saúde, tendo como foco a linguagem musical, de maneira a criar condições para que todas as pessoas presentes em uma instituição de saúde possam reivindicar a sua dignidade e a sua unicidade, num encontro livre e gratuito, encontro esse que se articula através da música. Trata-se de um profícuo e promissor diálogo entre a Cultura e a Saúde.

Embora desvinculados da responsabilidade de curar, cuidar ou, mais precisamente da obtenção de quaisquer efeitos terapêuticos (embora cientificamente evidenciáveis), esses músicos atuam verdadeiramente como agentes de promoção da saúde, fazendo residir na música (fundamental por si só) a sua estratégia, visto que a promoção da saúde não é restrita aos profissionais da área, mas sim, é responsabilidade de cada cidadão no âmbito de sua atuação profissional, se concebermos a saúde como um bem socialmente compartilhado e sobre o qual cada ser humano tem sua parcela de contribuição em relação ao outro. Cabe ressaltar ainda, que promoção da saúde não é sinônimo de prevenção de doenças. Os indivíduos e as coletividades precisam ser tratados das doen- ças que os acometem, que também devem proteger-se das doenças e serem protegidos contra elas, a Promoção da Saúde propõe para além disso, que estas doenças sejam, elas próprias minimizadas, erradicadas, eliminadas do mundo, do meio ambiente, das cidades, etc. Isso requer espaços urbanos, espaços institucionais (incluídas as instituições de longa permanência) ou privados mais adequados, que contribuam para cidades saudáveis ${ }^{(8)}$. Urge, a partir dessas considerações, na condição de profissionais de saúde (ou com ela envolvidos), promover o deslocamento do nosso foco, da doença para a saúde e a música nos hospitais oferece reflexões nesse sentido. É o que temos observado em nossos estudos envolvendo a música ao longo dos últimos anos ${ }^{(9)}$.

A promoção da saúde tem muito mais a ver com os determinantes maiores do processo saúde-doença, e por isso é que apresentamos anteriormente o impacto que o isolamento social, comumente existente nas instituições de longa permanência, exerce sobre os idosos. As mudanças sociais relacionadas ao processo de enveIhecimento influem marcadamente na perda da qualidade de vida, mas que de alguma forma, a música se propõe a resgatá-la. Com isso busca-se, de fato, o deslocamento da abordagem do paciente como objeto de cura para torná-lo sujeito, assim como se busca enfatizar a saúde ao invés da doença. Entretanto, pouco se conhece ainda, até mesmo sobre as motivações internas que levam à implementação de atividades como essa e à abrangência de seu desenvolvimento.

A interface deste trabalho com a Enfermagem é evidenciada pelo crescente interesse sobre a temática Música e Saúde na última década em nosso meio, embora seja objeto de atenção desde Florence Nightingale ${ }^{(10)}$, além de configurar como intervenção de enfermagem na Classificação de Intervenções de Enfermagem (NIC - Nursing Interventions Classification) $)^{(11)}$ e, assim sendo, constitui conhecimento relevante para o planejamento do cuidado na assistência aos idosos.

Acreditamos que a música nas instituições de saúde é necessária para a preservação da linguagem para os idosos em processos efetivos de comunicação. Acreditamos ainda, que novas atividades profissionais voltadas para novas formas de inserção ou outras que venham trazer formas estimulantes de pensar devem ser avaliadas por poderem constituir-se também, em fonte de ânimo e de desenvolvimento dos idosos. Este artigo, portanto, objetiva analisar a percepção de músicos que atuam em instituições de longa permanência em Portugal e na França, no que concerne à experiência no desenvolvimento de sua atividade junto aos idosos, com foco, principalmente, no relacionamento interpessoal. Sob tal perspectiva, o material empírico aqui apresentado sumariamente, dados os limites deste trabalho, permitirá novos olhares e novas escutas tanto para a Enfermagem quanto para a Gerontologia, assim como para os músicos que atuam na área da saúde. 


\section{MÉTODO}

Adotamos, no presente estudo, a abordagem qualitativa por ser definida como aquela que se preocupa com um nível de realidade que não pode ser quantificado e que trabalha com o universo dos significados, motivos, valores e atitudes, que, por sua vez, correspondem a um espaço mais profundo das relações, dos processos e dos fenômenos que não podem ser reduzidos à operacionalização de variáveis ${ }^{(12)}$. Foram convidados para a pesquisa oito músicos que atuavam há mais de um ano em Instituições de Longa Permanência em Portugal e na França, formados pelo Centro de Formação de Músicos Atuantes, da Universidade Marc Bloch, dos quais, seis músicos (quatro portugueses e dois franceses) aceitaram participar como sujeitos da pesquisa.

Após a aprovação do projeto de pesquisa pelo Comitê de Ética da Instituição de origem (sob n. 24/05) de um dos autores, os sujeitos da pesquisa, após compreensão do objetivo da pesquisa e mediante a anuência em Termo de Consentimento Livre e Esclarecido (nos respectivos idiomas), responderam a um questionário com cinco questões abertas que enfocavam a experiência de levar música aos idosos institucionalizados, o relacionamento interpessoal entre o músico e os idosos, a intenção do músico ao desenvolver essa atividade, as dificuldades na realização do trabalho e os critérios para seleção do repertório musical. A coleta de dados junto aos músicos portugueses ocorreu em outubro-novembro/2005 e com os músicos franceses em maio-junho/2006. Para análise, os relatos verbais escritos portugueses foram adaptados para a língua portuguesa (Brasil) e os relatos franceses foram submetidos à tradução livre validada com uma professora de língua francesa nativa.

Para a organização e apresentação dos dados, foi utilizado o método do Discurso do Sujeito Coletivo (DSC) que busca resgatar o discurso coletivo a partir dos discursos individuais ${ }^{(13)}$. Optamos por realizar essa análise, uma vez que o DSC é uma descrição ou representação discursiva do imaginário social, que constitui uma representação social na forma de matéria-prima discursiva. Tal matéria prima permite que os indivíduos produzam pensamentos, crenças, sentimentos, entre outros, para serem inter-relacionados na sociedade em que vivem e nos grupos a que pertencem. Tal metodologia, portanto, foi considerada aplicável aos músicos que foram submetidos ao mesmo curso de formação para desenvolverem suas atividades em instituições de saúde.

A atuação dos músicos relatada foi apreendida mediante a identificação de Idéias Centrais - (IC) e das Expressões-Chave (ECH). As expressões-chave são constituídas por transcrições literais de parte dos depoimentos, que permitem o resgate do que é essencial no conteúdo discursivo dos segmentos em que se divide o depoimento; a idéia central de um discurso pode ser entendida como a(s) afirmação(ções) que permite(m) traduzir o essencial do conteúdo discursivo explicitado pelos sujeitos em seus depoimentos; e o Discurso do Sujeito Coletivo é a reconstrução, com pedaços de discursos individuais, de tantos discursos-síntese quantos forem necessários, para expressar um dado pensar ou representação social sobre um fenômeno ${ }^{(13)}$.

\section{RESULTADOS E DISCUSSÃO}

A seguir apresentamos a análise dos cinco temas que emergiram dos relatos dos músicos com seus respectivos discursos do sujeito coletivo e idéias centrais.

\section{Tema I: A percepção dos músicos sobre sua atuação}

\section{A atuação do músico a partir de sua formação acadêmica}

DSC 1 - A minha formação acadêmica preparou-me para estar num palco. Para ser o centro da apresentação musical em que me enquadrava. Entre mim e o público a distância física sempre foi marcada por um estrado que eleva a minha posição em relação aos que me ouvem. Não comunicamos diretamente, não nos relacionamos e não nos ajustamos uns aos outros no diálogo musical. O programa da apresentação (concerto ou outro gênero de espetáculo) é preparado e apresentado. O artista dá a sua interpretação da obra sem querer saber da interpretação feita pelos personagens do público.

Eu tive a oportunidade para tocar em orquestras diante de platéias numerosas (lendo partituras). Eu pude tocar em pequenos grupos de pop rock, funk, jazz, world music, diante de públicos em bares ou na ocasião de festivais (tocando de cor). Pela minha formação universitária de músico atuante na escola, eu tive a oportunidade de preparar espetáculos de música com crianças a fim de que elas pudessem apresentá-los no final do ano para os pais de alunos. Todas estas experiências musicais são da ordem do espetáculo. O público vai ao encontro dos músicos em uma data e um horário definido ( $1 \mathrm{~h} 30$ de concerto para o mesmo público), em um local de apresentação definido (sala de concerto), onde as peças tocadas são de-finidas (programação) e pertencem a um mesmo estilo (Concerto de rock, concerto clássico, concerto de reggae...).

A atuação junto aos idosos institucionalizados tem caráter singular, enriquecedor e gratificante para os músicos.

DSC 2 - A experiência de levar música a idosos institucionalizados é qualquer coisa de extraordinário. É em todos os sentidos, diferente de qualquer coisa que fiz, pensei fazer ou me preparei para fazer. Esta experiência de levar a música a idosos institucionalizados é um ato de entrega, de amor e de retorno direto e muitas vezes imediato. A experiência de levar a música até junto dos idosos institucionalizados é extremamente rica. Ao recebermos as suas reações enriquecemo-nos todos os dias. A experiência da intervenção junto de idosos institucionalizados é bastante gratificante do ponto de vista humano. Eu des- 
cobri um outro modo de fazer música. O aspecto frontal público-artista (em que o músico fica no palco e o público assiste da platéia) não existe mais. As pessoas idosa,; as famílias, a equipe do serviço, participam e se tornam os atores da atuação do músico. Eu aprendi muitas coisas as quais eu não esperava. É um trabalho verdadeiramente enriquecedor que requer reais qualidades, mas, sobretudo muitas competências diversas. Propor esta ação junto às pessoas idosas tornou-se para mim uma verdadeira experiência de vida. Eu aprendo a conhecer os limites da pessoa, não exigir performance de sua parte, compreender o que ela deseja verdadeiramente e, sobretudo, respeitar suas escolhas.

\section{A atuação do músico junto aos idosos institucionalizados é uma experiência relacional, de contato humano.}

DSC 3 - Quando Ihes levo a música abrem-se portas do Ser, que se pensavam fechadas nestes ido sos. Quando tocam conosco, quando cantam e participam como sabem e como os seus corpos e mentes permitem, não há idade nesse momento! Não há dor, não há limites e já não há tempo! Há somente o estar naquele momento de música e relacionamento. Há a pessoa! É isso que vejo nesta minha experiência com eles. É entrar em contato com pessoas que, de certa forma, perderam algo da sua vida passada. Eu tenho a chance de poder parar ou continuar a música em função da pessoa que está à minha frente. A gente aprende a olhar para as pessoas como elas são, sem julgamento.

Os DSC 1 e 2 apresentam a apreensão da experiência dos músicos junto aos idosos institucionalizados. Nesse contexto, o encontro entre os músicos e os idosos, na percepção dos primeiros, parece constituir um momento bastante singular em que o relacionamento acontece. Embora essa visão unilateral (a partir do músico) seja a maior limitação deste estudo e considerando que a comunicação é uma via de mão dupla, a percepção da experiência dos músicos parece ser construída a partir da relação com os idosos e que sustenta tanto o seu discurso como a continuidade de suas atividades nessas instituições.

Mais do que singular e diferente da atuação artística, para os quais receberam formação acadêmica, os músicos percebem a experiência como enriquecedora à medida que lhes descortina novas competências e experiências pessoais no âmbito do estabelecimento de trocas e de contato humanos, como observado no DSC 3.

À semelhança do que é preconizado por Peplau, para a Enfermagem em sua Teoria das Relações Interpessoais, o crescimento pessoal é compartilhado pelos sujeitos envolvidos no relacionamento interpessoal ${ }^{(14)}$.

\section{Tema II: O relacionamento entre os músicos e os idosos}

A relação de proximidade e reciprocidade é construída e acontece em diversos níveis entre os músicos e os idosos

DSC 4 - Com alguns existe já uma relação muito próxima, com alguns pacientes com demência avançada a cada encontro é quase como se fosse o primeiro e por isso o relacionamento que tenho com eles é distinto daquele que eles têm comigo. Com outros ainda, principalmente aqueles com quem não estive individualmente, o relacionamento é mais superficial. Crio com o paciente um momento que é só nosso. Nesse momento estou $100 \%$ para ele/ela. Como nos vemos todas as semanas este relacionamento vai também tomando outras formas. Criam-se laços e amizades. Passam a fazer parte da minha vida e da minha história. O relacionamento com os pacientes vai sendo desenvolvido ao longo das intervenções. Cria-se uma espécie de amizade baseada na música que é a linguagem principal que utilizamos. Através da música associada à presença e ao olhar, passam muitas emoções e sentimentos que nos tocam reciprocamente e que tornam estes momentos verdadeiramente significativos. Quando esta conexão acontece, a relação pessoa idosa/músico atuante se torna uma relação de homem para homem. A relação se torna fusão, eu me vejo, ou melhor, eu existo através do olhar da pessoa idosa, e eu tenho a esperança que a pessoa idosa exista através do meu olhar.

A música ajuda a superar diferenças e possíveis obstáculos ao relacionamento

DSC 5 - Muitas vezes a sensação que eu tenho ao entrar nestas instituições é a de que as pessoas se tornaram ilhas, que circulam num mesmo espaço, mas, muitas delas, se encontram perdidas. Levar a música a estas pessoas é proporcionar um contacto humano especial. O físico da pessoa às vezes pode causar repulsa. Depois, a gente pode não mais ligar para esse fato e rapidamente compreendemos que o mais importante é o que se encontra em seu coração. $E$ isto é algo que precisamos todos os dias, com qualquer pessoa. Eu sinto que quando a música conecta os olhares, as idades desaparecem (Eu não sou mais o jovem músico, a pessoa na minha frente não é mais a pessoa enrugada ou demente). A troca do olhar, a troca musical, o senso do toque, apaga a aparência física, os odores desagradáveis...

O relacionamento interpessoal é conscientemente buscado pelos músicos que percebem a qualidade dessa interação em diferentes níveis, uma vez que variam de um encontro superficial, em alguns casos, até encontros muito profundos, de caráter existencial. Tal atitude revela que não se trata de simplesmente levar música ao ambiente. Ela constitui sim, esse convite ao encontro, a uma cumplicidade entre sujeitos livres, um diálogo não verbal de compaixão (dando suporte aos sentimentos de dor ou tristeza), de complacência (dando suporte aos sentimentos do prazer e da felicidade), um convite à curiosidade ou à descoberta, ao desenvolvimento da potencialidade existente nos idosos. A música (a obra de arte e a manifestação cultural no geral), desde a mais complexa até a canção mais simples, é uma formalização simbólica ou poética de uma problemática (formal, expressiva, subjetiva...) Ela procura nomear ou evocar o seu objeto (polissêmico). E, nomeando, a música nos convida a nomear também por nossa vez, se a aceitamos como uma forma de nos encontrarmos conosco mesmo ou com o outro. A música, a obra de arte, nos convi- 
da a nomear e a nos nomear, a nos projetar em um espaço próximo e longínquo ao mesmo tempo; espaço evocativo, que nos chama para um mundo libertado da violência de ser a verdade, como nas palavras de T.W. Adorno: a arte é $a$ magia libertada de ser a verdade ${ }^{(15)}$.

Essas considerações conduzem-nos a reflexões sobre a subjetividade. O DSC 4 permite-nos inferir que a relação estabelecida pelos músicos com os idosos procura caracterizar uma relação $E u-T u^{(7)}$. Por outro lado, no DSC 5 observamos que a pouca familiaridade dos músicos com a aparência física, odores e fatores relacionados a doenças que os idosos podem apresentar, causam impacto sobre eles, mas que logo se dissipa à medida que a música possibilita o contato entre eles para além da dimensão física.

Para entendermos a relevância dessa atitude poderíamos nos questionar qual o tipo de relação mais comum de ser observada nas Instituições de Longa Permanência, entre profissionais e pacientes, entre os próprios pacientes, entre os familiares e os pacientes. Embora estejamos assistindo a um aumento exponencial de relações tipo Eu-Isso na sociedade contemporânea em geral, não nos aventuramos a responder, pois nos parece mais prudente deixar para cada um esse julgamento, a partir das próprias experiências profissionais. Vale ressaltar apenas que somente as relações tipo Eu-Tu é que podem tornar factível a desejada convivência ética entre os seres humanos.

\section{Tema III: A intenção dos músicos ao atuarem junto aos idosos institucionalizados}

A percepção dos músicos sobre a realidade dos idosos institucionalizados e a intenção de transformação dessa realidade

DSC 6 - Os idosos em instituição vivem habitualmente numa grande solidão e poder estar alguns minutos com cada um deles é qualquer coisa que me deixa muito feliz, depois porque é levar um pouco do exterior à instituição, habitualmente muito virada para dentro, porque este exterior faz parte da história e experiência de vida dos idosos e a música traz a lembrança desta vida que foi e ajuda a dar sentido à vida que é. Acho que sem dúvida é uma forma de retirar os idosos da sua rotina (que quase na totalidade é imposta), e realmente proporcionar um espaço em que voltam a ter os seus direitos, e escolhas como qualquer ser humano. A minha intenção quando atuo junto aos idosos é de permitir-lhes o contato com algo que, aparentemente, nada tem a ver com essas instituições. É ajudar na melhoria da qualidade de vida dessas pessoas! Proporcionar momentos de prazer, de tranqüilidade, de consolo, de vida e de partilha. Pretendo, portanto, que a música contribua para a sua dignidade pessoal. A intenção principal é que através da música os idosos possam voltar a ter um momento, um espaço em que realmente possam sair da instituição, em suma, humanizar a instituição. Eu trago a plenitude da minha presença, minha juventude, meu profissionalismo, meu sentimento para um bem-estar da pessoa institucionalizada. Passar momentos preciosos e fortes com pessoas idosas permite levar vida para elas.

\section{A intenção de estabelecer canais de comunicação}

DSC 7 - A minha intenção junto dos idosos é sempre tentar estabelecer canais de comunicação, encontrar-me com cada um deles no seu íntimo e proporcionar encontros entre eles e entre idosos e profissionais. Permitir que se sintam pessoas que continuam a poder comunicar com os outros e a tirar prazer disso.

\section{Intenções diversas}

DSC 8 - Trazer a cultura para o estabelecimento. Surpreender, acompanhar, compartilhar, fazer descobrir os sons, transformar o ambiente sonoro, reunir as pessoas da instituição em volta da música (as famílias, pacientes, pessoal), criar, descobrir novas modalidades de atuação.

A intencionalidade da atividade dos músicos junto aos idosos é bastante variada. Os músicos apresentam o desejo de resgatar o prazer e proporcionar qualidade de vida aos idosos, balizados não só pelo imaginário social acerca da institucionalização, como também pelo contato direto com essa dura realidade. A qualidade de vida é a condição humana resultante de um conjunto de parâmetros individuais e sócio-ambientais, que pode ou não ser modificado, caracterizando as condições em que vivem os seres humanos. Iniciativas voltadas ao seu incremento vêm ao encontro da satisfação das necessidades qualitativas radicais humanas (convivência, introspecção, brincadeira, amizade, amor) no sentido de reduzir as distâncias que segregam ${ }^{(16)}$.

Os idosos, em grande número de casos, ressentem-se da ausência de relações, uma vez que a rede social apresenta uma tendência a diminuir à medida que se envelhece e que se agrava ainda mais a partir da institucionalização ${ }^{(5)}$. Associa-se a isto a redução das oportunidades de substituição para essas perdas e, os músicos, por alguns momentos, possibilitam o preenchimento dessa lacuna. De certa forma, as instituições ao permitirem o desenvolvimento de tal atividade passam a atuar como mediadoras e promotoras de uma nova possibilidade de estabelecimento de rede de apoio, uma vez que pode contribuir para que ocorram também novas relações entre os internos, consonante aos DSC 6, 7 e 8 pelo caráter agregador da música que possibilita minimizar o isolamento social.

\section{Tema IV: A percepção dos músicos sobre as dificuldades para realização do trabalho junto aos idosos institucionalizados}

\section{Dificuldades de comunicação interpessoal}

DSC 9 - Quando estamos perante grandes grupos, nessas situações é por vezes difícil criar os tais canais de comunicação, estabelecer pontes entre os presentes e encontrar realmente cada um dos idosos. Para mim, é a aproximação e a verdadeira parceria com a equipe de profissionais de saúde. Eu tenho muita dificuldade em ter segurança para ir vê-los e fazê-los se beneficiar da minha música. O lidar com espaços com muitos pacientes, 
sobretudo se for um lugar onde as pessoas se encontrem muito afastadas umas das outras. Dificulta uma comunicação mais profunda e torna o acontecimento mais superficial.

\section{Dificuldades relativas ao aprimoramento individual}

DSC 10 - A maior dificuldade que me surge tem a ver com a necessidade do músico ter de se renovar em cada intervenção, ou seja, o pior que pode acontecer ao músico atuante é cair na rotina, perder a capacidade de surpreender e ser surpreendido. É também muito desgastante por todo o trabalho, concentração e entrega que exige. Eu devo ser exigente comigo e estar disponível. Minha dificuldade maior é achar o tempo para renovar meu repertório como também meu instrumentarium. Meu principal medo é de me cansar musicalmente e, por conseqüência, cansar as pessoas ao redor de mim. Talvez, também às vezes, uma falta de originalidade.

\section{Dificuldades em lidar com a institucionalização dos idosos}

DSC 11 - Para mim, a maior dificuldade deste trabalho é lidar com este abandono, solidão, sofrimento (muitas vezes não só físico!) e o formatar, pelas Instituições, das pessoas idosas.

Os músicos apontam suas maiores dificuldades na realização da atividade junto aos idosos, na qual nem sempre a relação interpessoal almejada é alcançada prontamente, quando os idosos encontram-se em grupos (DSC 9) ou quando precisam vencer as próprias angústias desencadeadas pelos quadros de realidade, sob a sua ótica, que se apresentam revestidos de abandono, solidão, sofrimento e o impacto da institucionalização sobre os idosos (DSC 11). A institucionalização tem reforçado os estereótipos relatados (também observados na enfermagem), e que refletem a situação de exclusão dos idosos, os quais somente poderão ser modificados a partir de novas concepções sociais sobre o envelhecimento, que devem ser iniciadas nas famílias, para que se possa proporcionar melhor qualidade de vida ao idoso(17) ${ }^{(17}$ que pode contribuir também, para modificar as características das Instituições de Longa Permanência.

Os músicos ressentem-se ainda, de um espaço maior a ser conquistado junto à equipe multiprofissional que facilite a relação interpessoal com esse segmento (DSC 9). E, mais do que dificuldade, a atualização musical parece constituir um desafio constante para a atuação junto aos idosos (DSC 10).

\section{Tema V: Critérios para escolha de repertório musical}

\section{Critérios musicais}

DSC 12 - Música tradicional. O repertório é escolhido primeiro numa linha tradicional e popular. Não há limitações na escolha do repertório: escolho erudito, ligeiro, jazz, ambientes sonoros criados pelos instrumentos feitos por nós, etc. Música é música e chega mais rápido que os rótulos com que a classificamos...!

\section{Critérios que consideram características pessoais dos} pacientes

DSC 13 - Tudo depende da pessoa, do estado da pessoa (desperta, cansado, queixoso, melancólico...). Para a escolha de repertório tento saber um pouco da história do paciente, de onde ele vem, qual a sua profissão, gostos pessoais, de acordo com estas informações tento criar um repertório inicial base. Tenho em atenção, a origem e as características da pessoa - o local onde nasce u,se teve ou não filhos, os seus gostos pessoais, o seu estado emocional no momento... O repertório é pensado tendo em conta a origem, e a idade das pessoas. Se isso se passa em um quarto, os objetos que podem estar lá, as fotografias com netos, um marido... Se a pessoa está cansada, se ela deseja canções humorísticas, canções de ninar... Também é possível falar com os pacientes para perguntar-lhes que tipo de canção gostaria de ouvir. É também possível conhecer a história da pessoa: a profissão que ela teve...

\section{Critérios pessoais dos músicos}

DSC 14 - (Depende) do meu humor.

\section{Critérios que consideram o ambiente}

DSC 15 - Depende do local, do ambiente sonoro e visual.

\section{Critérios Intuitivos}

DSC 16 - Procuro utilizar repertório diversificado, de modo a poder surpreender. A diversidade é muito importante, não só para que não haja cansaço, mas também para estimular o interesse pelo novo e pelo diferente. Depende muito da reação ao longo da intervenção e das sessões seguintes. Tento também trazer repertório de diferentes estilos e a questão dos ambientes sonoros, para surpreender, evocar. Também importante na escolha do repertório é incluir estilos diversos para dar a conhecer outros tipos de música. No momento da intervenção a escolha das músicas é uma reação à situação, visto que não há qualquer ordem de músicas pré-definidas. (Depende) do momento, da metereologia, do momento do dia, do período do ano (hora de café, Noel, o outono, a primavera, a chuva, o sol...).

Falar de critérios quando se pensa na música nos hospitais é sempre um aspecto crítico. Para os músicos os critérios não se apresentam bem definidos, o que era esperado, uma vez que fazer música é o cerne da sua atividade sem a intenção, a priori, de resultados terapêuticos, embora o desejo de melhorar a qualidade de vida dos idosos tenha sido relatada. Os critérios são livres considerando características sonoro-musicais, características dos pacientes, como os preconizados por algumas linhas na musicoterapia, considerando ainda, critérios pessoais do músico (como o humor) e com forte apelo intuitivo. À semelhança do método de Imagens Guiadas e Música (GIM), o conhecimento musical reflete na escoIha do melhor programa para atender as necessidades dos pacientes ${ }^{(18)}$, embora sua criadora indique que compreender a música não exige um método específico de análise, pois é um processo de estar em ressonância no 
qual o ouvinte se torna 'UM' com a música quando uma suficiente sensibilidade ao afetivo e ao intuitivo e às respostas intuitivas à música tenha sido desenvolvida. Trata-se de um modo de escuta afetiva-intuitiva como ela denomina a partir e através da constante utilização dos repertórios do $\mathrm{GIM}^{(19)}$.

Entretanto, a pesquisa sobre a influência da música e os seus efeitos na práxis não só dos músicos atuantes, mas de qualquer profissional que a tenha com objeto é de suma importância, para que ela possa acontecer de forma segura e efetiva junto aos idosos institucionalizados ou junto a outras populações hospitalizadas, de forma que ela não corra o risco de ser banalizada ou aconteça de forma indiscriminada.

\section{CONSIDERAÇÕES FINAIS}

O estudo permitiu apreender que a experiência dos músicos atuantes juntos aos idosos institucionalizados

\section{REFERÊNCIAS}

1. World Health Organization (WHO). Life in the 21st century: a vision for all. The World Health Report. Geneva; 1998.

2. Kalache A, Veras RP, Ramos LR. The ageing of the world's population: a new challenge. Rev Saúde Pública. 1987;21(3):200-10.

3. Beauvoir S. A velhice. Rio de Janeiro: Nova Fronteira; 1990.

4. Cortelletti IA, Casara MB, Herédia VBM. Idoso asilado: um estudo gerontológico. Caxias do Sul: EDIPUCRS; 2004.

5. Freire Junior RC, Tavares MFL. A saúde sob o olhar do idoso institucionalizado: conhecimento e valorizando sua opinião. Interface Comun Saúde Educ. 2005;9(16): 147-58.

6. Both A. Linguagem, pensamento e afeto: fundamentos educacionais para o desenvolvimento de idosos. In: Pasqualotti A, Portella MR, Bettinelli LA. Envelhecimento humano: desafios e perspectivas. Passo Fundo: UPF; 2004. p. 19-35.

7. Buber M. Eu e Tu. São Paulo: Cortez; 1977.

8. Lefèvre F, Lefèvre AMC. Promoção de saúde: a negação da negação. Rio de Janeiro: Veira \& Lent; 2004.

9. Leão ER, Bussotti EA, Aquino CR, Canesin, AC, Brito RP. Uma canção no cuidar: a experiência de intervir com música no hospital. Nursing (São Paulo). 2005;8(82): 129-34.

10. Ninghtingale F. Notes on nursing: what it is, and what it is not [text on the Internet]. New York: Appleton; 1860. [cited 2006 Jul 20]. Available from: http://digital. library. upenn.edu/women/nightingale/nursing/nursing.html se traduz pela busca livre do exercício desta atividade, aliada à busca consciente do relacionamento interpessoal, acrescida ainda da intencionalidade expressa no discurso coletivo que resultam no comprometimento profissional, social e humano dos músicos analisados.

A comunicação mais profunda é um desafio, e embora às vezes permeada por sentimentos de impotência e até mesmo de frustração representadas pelas dificuldades inerentes ao processo, quando a relação $E u$ - $T u$ acontece desencadeia nos músicos emoção e sentimentos de felicidade, afetividade e até mesmo de gratidão, pois reconhecem que o encontro, mediado pela música, possibilitou o seu crescimento pessoal naquele momento agregando valor à sua vida.

A percepção dos idosos, assim como de familiares/ acompanhantes e dos profissionais de saúde envolvidos merecem ser investigadas de forma a compor de forma mais abrangente a especificidade da atuação dos músicos nos hospitais.

11. McCloskey JC, Bulechek GM. Nursing Interventions Classification (NIC). $2^{\text {nd }}$ ed. St. Louis: Mosby; 1996.

12. Minayo MCS. Pesquisa social: teoria, método e criatividade. Petrópolis: Vozes; 1994. Ciência, técnica e arte: o desafio da pesquisa social; p. 9-29.

13. Lefevre F, Lefevre AMC. Os novos instrumentos no contexto da pesquisa qualitativa. In: Lefèvre $F$, Lefèvre $A M C$, Teixeira JJV, organizadores. O discurso do sujeito coletivo: uma nova abordagem metodológica em pesquisa qualitativa. Caxias do Sul: EDUCS; 2000. p. 11-35.

14. Almeida VCF, Lopes MVO, Damasceno MMC. Teoria das relações interpessoais de Peplau: análise fundamentada em Barnaum. Rev Esc Enferm USP. 2005;39(2):202-10.

15. Flusser $V$. Vers une définition de la musique em millieu de la santé. Les Cahiers Mus. 2005; 1(1):3-6.

16. Gáspari JC, Schwartz GM. O idoso e a ressignificação emocional do lazer. Psicol Teor Pesqui. 2005;21(1):69-76.

17. Santos NC, Meneghin P. Concepções dos alunos de graduação em enfermagem sobre o envelhecimento. Rev Esc Enferm USP. 2006;40(2):151-9.

18. Barcellos LRM, organizadora. Musicoterapia: transferência, contratransferência e resistência. Rio de Janeiro: Enelivros; 1999. Transferência e contratransferência e resistência no método Bonny de "Imagens Guiadas e Música" - GIM; p. 89-122.

19. Bonny H. Body listening: a new way to review the GIM tapes. J Assoc Music Imag. 1993; (2):3-10. 